ДАРЕНСЬКИЙ О. М., д.т.н., професор (Український державний університет залізничного транспорту),

ШРАМЕНКО В. П., к.т.н., доцент (Український державний університет залізничного транспорту),

ТУЛЕЙ Ю. Л., заступник начальника філії «Південна залізниця» (ПАТ «Укрзалізниця»), ДУДІН О. А., к.т.н., доцент (Український державний університет залізничного транспорту), ЛЕЙБУК Я. С., аспірант (Український державний університет залізничного транспорту)

\title{
Математична модель колії, яка мас інерційні характеристики, під дією швидкісного рухомого складу
}

Розроблено моделі $і$ методи визначення приведеної вертикальної жорсткості рейкової нитки в точці контакту колеса і рейки, яка враховує пружні і геометричні характеристики рейок, жорсткості опор, відстані між ними і розподілену масу колії. Величина иієї жорсткості змінна в часі для кожного колеса у будь-який момент часу $i$ відрізняється для різних коліс екіпажу. Запропонована математична модель реалізована $в$ програмному комплексі Matlab i дасть змогу надалі виконати чисельні дослідження динаміки взаємодї колії $i$ рухомого складу.

Ключові слова: балка на опорах, математична модель, динамічна система, "екіпаж-колія", приведена жорсткість.

\begin{abstract}
Вступ
Дослідження роботи залізничної колії під дією навантаження від рухомого складу чисельними методами дає змогу отримувати інформацію про особливості дії на колію і особливості напруженодеформованого стану усієї конструкції в різних умовах експлуатації при значно менших матеріальних i фінансових витратах у порівнянні 3 експериментальними методами. Чисельні методи так само дають можливість точно визначати початкові розрахункові дані, що $є$ практично неможливим при проведенні експериментальних робіт.

Проте застосовувати чисельні методи можна тільки тоді, коли математичні моделі адекватно відображають реальну роботу як динамічної системи "екіпаж-колія", так і конструкції колії. Це повною мірою стосується до моделювання взаємодій колії і рухомого складу. Таким чином, моделювання взаємодії колії і рухомого складу $\epsilon$ актуальним завданням.
\end{abstract}

\footnotetext{
Аналіз досліджень і публікацій

Нині найбільш вживаною $є$ модель колії, за якої рейки мають вигляд балок нескінченної довжини, що спираються на суцільну пружну основу. На підставі теоретичних досліджень Е. М. Бромберга, М. Ф. Веріго, А. Я. Когана, Г. М. Шахунянца [1-4] і інших учених розроблено математичні моделі взаємодії колії і рухомого складу, напружено-
}

деформованого стану колії, які базуються на цій розрахунковій схемі. Численні експериментальні дослідження показали, що для умов магістральних залізниць теоретичні та експериментальні результати мають хорошу збіжність.

Проте ряд вчених (К. Д. Білих [5], Н. С. Никеров [6] та ін.) вважають, що для умов залізниць така розрахункова схема надмірно ідеалізує колію і іii технічний стан. В. В. Рибкін, розраховуючи колію як балку на багатьох пружних опорах зі змінними характеристиками жорсткості під дією статичного навантаження, показав, що застосування методів пружної основи дає занижені на 17-24 \% результати [7]. У роботі [8] подано математичні моделі динамічної системи "екіпаж-колія", в основі яких прийнята розрахункова схема колії як балки на багатьох пружнодисипативних опорах 3 нелінійними характеристиками. Реалізація цих моделей у програмній системі Matlab дає можливість визначати просторові сили дій екіпажів на колію.

\section{Визначення мети та задачі дослідження}

Проблема, вирішенню якої присвячено цю роботу, полягає у відсутності на сьогодні математичної моделі колії як балки на багатьох пружно-дисипативних опорах з урахуванням інерційних характеристик колії. Розроблення такої моделі істотно підвищить точність розрахунків.

() О. М. Даренський, В. П. Шраменко, Ю. Л. Тулей, О. А. Дудін, Я. С. Лейбук, 2018 
Метою дослідження є розроблення математичної моделі роботи колії як балки на пружних опорах, що має інерційність під дією навантаження швидкісного рухомого складу.

\section{Основна частина дослідження}

У роботі [9] було отримано диференціальне рівняння поперечних коливань балок під дією поперечного навантаження, яке змінюється за гармонічним законом :

$y(x)=y_{0} A s x+\frac{y_{0}^{\prime}}{s} B s x-\frac{M_{0}}{s^{2} E I} C s x-\frac{Q_{0}}{s^{3} E I} D s x-\frac{q}{s^{4} E I}\left(A_{s x}-1\right)$, де $y_{0}, y_{0}^{\prime}, M_{0}, Q_{0}-$ початкові параметри, $s^{4}=\frac{m \theta^{2}}{E I}$, поперечна сила в початку координат;

$A s x, B s x, C s x, D s x$ - функції Крилова А. Н.;

$E$ - модуль пружності;

$I$ - момент інерції поперечного перерізу;

$S$ - характеристичне число, яке визначається співвідношенням:

$m$ - розподілена маса колії, яка бере участь у процесі коливань;

$\theta$ - частота коливань.

Розглянемо далі колію, у вигляді розрахункової схеми, поданої на рис. 1.

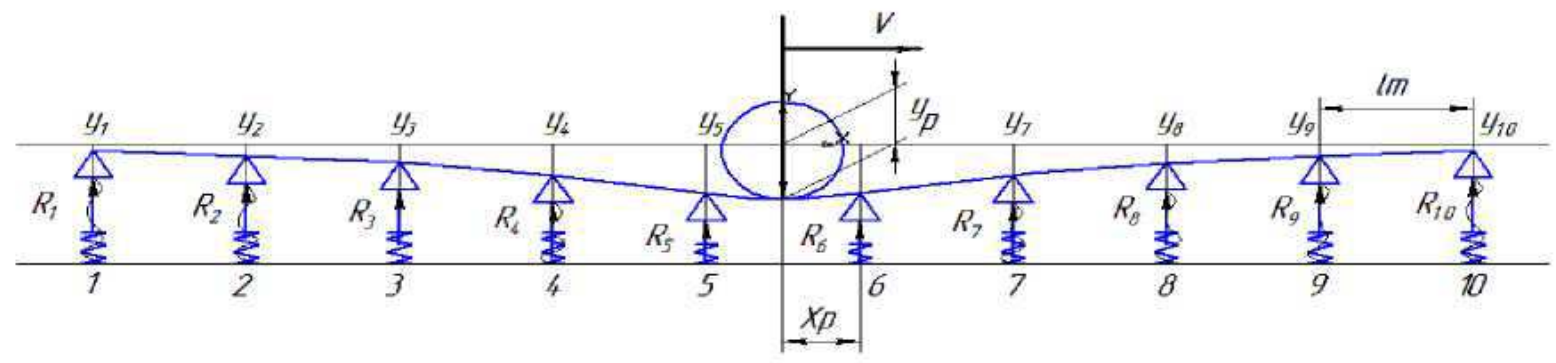

Рис. 1. Розрахункова схема рейкової нитки на пружних опорах під дією рухомої сили

Численні дослідження, результати яких містяться, наприклад, у [8], показали, що хвиля вигину рейки не поширюється далі 2,5 м від точки прикладення навантаження. Тому розглядаємо колію у вигляді балки на 10 опорах. При дії на колію зосередженої сили, яка рухається уздовж колії, рівняння (1) набуде такого вигляду:

$$
\begin{aligned}
& y(x)=\frac{1}{s^{3} E I}\left(-R_{1} D s\left(x-x_{1}\right)-R_{2} D s\left(x-x_{2}\right)-R_{3} D s\left(x-x_{3}\right)-R_{4} D s\left(x-x_{4}\right)-R_{5} D s\left(x-x_{5}\right)-\right. \\
& \left.-R_{6} D s\left(x-x_{6}\right)-R_{7} D s\left(x-x_{7}\right)-R_{8} D s\left(x-x_{8}\right)-R_{9} D s\left(x-x_{9}\right)-R_{10} D s\left(x-x_{10}\right)+P D s\left(x-x_{P}\right)\right)
\end{aligned}
$$

де

$R_{i}$ - реакція опор;

$P$ - колісне навантаження;

$x_{i}$ - відстань від кожної опори до перерізу, що розглядається.

Використовуючи основне рівняння (3), складемо рівняння прогинів для кожної опори при дії сили Р: 
$y(1)=\frac{1}{s^{3} E I}\left(-R_{1} D s\left(l_{u}-l_{u}\right)-R_{2} D s\left(l_{u}-2 l_{u}\right)-R_{3} D s\left(l_{u}-3 l_{u}\right)-R_{4} D s\left(l_{u}-4 l_{u}\right)-R_{5} D s\left(l_{u}-5 l_{u}\right)-\right.$

$\left.-R_{6} D s\left(l_{u}-6 l_{u}\right)-R_{7} D s\left(l_{u}-7 l_{u}\right)-R_{8} D s\left(l_{u}-8 l_{u}\right)-R_{9} D s\left(l_{u}-9 l_{u}\right)--R_{10} D s\left(l_{u}-10 l_{u}\right)+P D s\left(l_{u}-x_{P}\right)\right)$

$y(2)=\frac{1}{s^{3} E I}\left(-R_{1} D s\left(2 l_{u}-l_{u}\right)-R_{2} D s\left(2 l_{u}-2 l_{u}\right)-R_{3} D s\left(2 l_{u}-3 l_{u}\right)-R_{4} D s\left(2 l_{u}-4 l_{u}\right)-R_{5} D s\left(2 l_{u}-5 l_{u}\right)-\right.$

$\left.-R_{6} \operatorname{Ds}\left(2 l_{u}-6 l_{u}\right)-R_{7} \operatorname{Ds}\left(2 l_{u}-7 l_{u}\right)-R_{8} \operatorname{Ds}\left(2 l_{u}-8 l_{u}\right)-R_{9} \operatorname{Ds}\left(2 l_{u}-9 l_{u}\right)-R_{10} \operatorname{Ds}\left(2 l_{u}-10 l_{u}\right)+P D s\left(2 l_{u}-x_{P}\right)\right)$

$y(3)=\frac{1}{s^{3} E I}\left(-R_{1} D s\left(3 l_{u}-l_{u}\right)-R_{2} D s\left(3 l_{u}-2 l_{u}\right)-R_{3} \operatorname{Ds}\left(3 l_{u}-3 l_{u}\right)-R_{4} \operatorname{Ds}\left(3 l_{u}-4 l_{u}\right)-R_{5} \operatorname{Ds}\left(3 l_{u}-5 l_{u}\right)-\right.$

$\left.-R_{6} D s\left(3 l_{u}-6 l_{u}\right)-R_{7} D s\left(3 l_{u}-7 l_{u}\right)-R_{8} D s\left(3 l_{u}-8 l_{u}\right)-R_{9} \operatorname{Ds}\left(3 l_{u}-9 l_{u}\right)-R_{10} \operatorname{Ds}\left(3 l_{u}-10 l_{u}\right)+\operatorname{PDs}\left(3 l_{u}-x_{P}\right)\right)$

$y(4)=\frac{1}{s^{3} E I}\left(-R_{1} D s\left(4 l_{u}-l_{u}\right)-R_{2} D s\left(4 l_{u}-2 l_{u}\right)-R_{3} D s\left(4 l_{u}-3 l_{u}\right)-R_{4} D s\left(4 l_{u}-4 l_{u}\right)-R_{5} D s\left(4 l_{u}-5 l_{u}\right)-\right.$

$\left.-R_{6} D s\left(4 l_{u}-6 l_{u}\right)-R_{7} D s\left(4 l_{u}-7 l_{u}\right)-R_{8} D s\left(4 l_{u}-8 l_{u}\right)-R_{9} D s\left(4 l_{u}-9 l_{u}\right)-R_{10} D s\left(4 l_{u}-10 l_{u}\right)+P D s\left(4 l_{u}-x_{P}\right)\right)$

$y(5)=\frac{1}{s^{3} E I}\left(-R_{1} D s\left(5 l_{u}-l_{u}\right)-R_{2} D s\left(5 l_{u}-2 l_{u}\right)-R_{3} D s\left(5 l_{u}-3 l_{u}\right)-R_{4} D s\left(5 l_{u}-4 l_{u}\right)-R_{5} D s\left(5 l_{u}-5 l_{u}\right)-\right.$

$\left.-R_{6} D s\left(5 l_{u}-6 l_{u}\right)-R_{7} D s\left(5 l_{u}-7 l_{u}\right)-R_{8} D s\left(5 l_{u}-8 l_{u}\right)-R_{9} D s\left(5 l_{u}-9 l_{u}\right)-R_{10} D s\left(5 l_{u}-10 l_{u}\right)+P D s\left(5 l_{u}-x_{P}\right)\right)$

$y(6)=\frac{1}{s^{3} E I}\left(-R_{1} D s\left(6 l_{u}-l_{u}\right)-R_{2} D s\left(6 l_{u}-2 l_{u}\right)-R_{3} D s\left(6 l_{u}-3 l_{u}\right)-R_{4} \operatorname{Ds}\left(6 l_{u}-4 l_{u}\right)-R_{5} D s\left(6 l_{u}-5 l_{u}\right)-\right.$

$\left.-R_{6} D s\left(6 l_{u}-6 l_{u}\right)-R_{7} D s\left(6 l_{u}-7 l_{u}\right)-R_{8} D s\left(6 l_{u}-8 l_{u}\right)-R_{9} D s\left(6 l_{u}-9 l_{u}\right)-R_{10} D s\left(6 l_{u}-10 l_{u}\right)+P D s\left(6 l_{u}-x_{P}\right)\right)$

$y(7)=\frac{1}{s^{3} E I}\left(-R_{1} D s\left(7 l_{u}-l_{u}\right)-R_{2} D s\left(7 l_{u}-2 l_{u}\right)-R_{3} \operatorname{Ds}\left(7 l_{u}-3 l_{u}\right)-R_{4} \operatorname{Ds}\left(7 l_{u}-4 l_{u}\right)-R_{5} D s\left(7 l_{u}-5 l_{u}\right)-\right.$

$-R_{6} \operatorname{Ds}\left(7 l_{u}-6 l_{u}\right)-R_{7} \operatorname{Ds}\left(7 l_{u}-7 l_{u}\right)-R_{8} \operatorname{Ds}\left(7 l_{u}-8 l_{u}\right)-R_{9} \operatorname{Ds}\left(7 l_{u}-9 l_{u}\right)-R_{10} \operatorname{Ds}\left(7 l_{u}-10 l_{u}\right)+P D s\left(7 l_{u}-x_{P}\right)$

$y(8)=\frac{1}{s^{3} E I}\left(-R_{1} D s\left(8 l_{u}-l_{u}\right)-R_{2} D s\left(8 l_{u}-2 l_{u}\right)-R_{3} D s\left(8 l_{u}-3 l_{u}\right)-R_{4} D s\left(8 l_{u}-4 l_{u}\right)-R_{5} D s\left(8 l_{u}-5 l_{u}\right)-\right.$

$-R_{6} D s\left(8 l_{u}-6 l_{u}\right)-R_{7} D s\left(8 l_{u}-7 l_{u}\right)-R_{8} D s\left(8 l_{u}-8 l_{u}\right)-R_{9} D s\left(8 l_{u}-9 l_{u}\right)-R_{10} D s\left(8 l_{u}-10 l_{u}\right)+P D s\left(8 l_{u}-x_{P}\right)$

$y(9)=\frac{1}{s^{3} E I}\left(-R_{1} D s\left(9 l_{u}-l_{u}\right)-R_{2} D s\left(9 l_{u}-2 l_{u}\right)-R_{3} D s\left(9 l_{u}-3 l_{u}\right)-R_{4} D s\left(9 l_{u}-4 l_{u}\right)-R_{5} D s\left(9 l_{u}-5 l_{u}\right)-\right.$

$\left.-R_{6} D s\left(9 l_{u}-6 l_{u}\right)-R_{7} D s\left(9 l_{u}-7 l_{u}\right)-R_{8} D s\left(9 l_{u}-8 l_{u}\right)-R_{9} D s\left(9 l_{u}-9 l_{u}\right)-R_{10} D s\left(9 l_{u}-10 l_{u}\right)+P D s\left(9 l_{u}-x_{P}\right)\right)$

$y(10)=\frac{1}{s^{3} E I}\left(-R_{1} D s\left(10 l_{u}-l_{u}\right)-R_{2} D s\left(10 l_{u}-2 l_{u}\right)-R_{3} D s\left(10 l_{u}-3 l_{u}\right)-R_{4} D s\left(10 l_{u}-4 l_{u}\right)-R_{5} D s\left(10 l_{u}-5 l_{u}\right)-\right.$

$\left.-R_{6} D s\left(10 l_{u}-6 l_{u}\right)-R_{7} D s\left(10 l_{u}-7 l_{u}\right)-R_{8} D s\left(10 l_{u}-8 l_{u}\right)-R_{9} D 10\left(9 l_{u}-9 l_{u}\right)-R_{10} D s\left(10 l_{u}-10 l_{u}\right)+P D s\left(10 l_{u}-x_{P}\right)\right)$

У цих рівняннях відстань від найближчої опори до $A \cdot y=H$, точки прикладення навантаження визначається як:

$x_{P}=5 l_{u}+\left(1-\left\{\frac{x_{n i}}{l_{u}}\right\}\right) \cdot l_{u}$

де $\left\{\frac{x_{n i}}{l_{u}}\right\}$ - дробова частина співвідношення $\frac{x_{n i}}{l_{u}}$.

Систему (4) в матричном вигляді можна записати де $A$ - матриця пружних та інерційних характеристик колії;

$y$ - матриця невідомих деформацій опор;

$H$ - матриця зовнішнього навантаження.

Матриця пружних та інерційних характеристик колії має вигляд: як: 


$\left\{\begin{array}{cccccccccc}s^{3} E I & c D(l-2 l) & c D(l-3 l) & c D(l-4 l) & c D(l-5 l) & c D(l-6 l) & c D(l-7 l) & c D(l-8 l) & c D(l-9 l) & c D(l-10 l) \\ c D(2 l-l) & s^{3} E I & c D(2 l-3 l) & c D(2 l-4 l) & c D(2 l-5 l) & c D(2 l-6 l) & c D(2 l-7 l) & c D(2 l-8 l) & c D(2 l-9 l) & c D(2 l-10 l) \\ c D(3 l-l) & c D(3 l-2 l) & s^{3} E I & c D(3 l-4 l) & c D(3 l-5 l) & c D(3 l-6 l) & c D(3 l-7 l) & c D(3 l-8 l) & c D(3 l-9 l) & c D(3 l-10 l) \\ c D(4 l-l) & c D(4 l-2 l) & c D(4 l-3 l) & s^{3} E I & c D(4 l-5 l) & c D(4 l-6 l) & c D(4 l-7 l) & c D(4 l-8 l) & c D(4 l-9 l) & c D(4 l-10 l) \\ c D(5 l-l) & c D(5 l-2 l) & c D(5 l-3 l) & c D(5 l-4 l) & s^{3} E I & c D(5 l-6 l) & c D(5 l-7 l) & c D(5 l-8 l) & c D(5 l-9 l) & c D(5 l-10 l) \\ c D(6 l-l) & c D(6 l-2 l) & c D(6 l-3 l) & c D(6 l-4 l) & c D(6 l-5 l) & s^{3} E I & c D(6 l-7 l) & c D(6 l-8 l) & c D(6 l-9 l) & c D(6 l-10 l) \\ c D(7 l-l) & c D(7 l-2 l) & c D(7 l-3 l) & c D(7 l-4 l) & c D(7 l-5 l) & c D(7 l-6 l) & s^{3} E I & c D(7 l-8 l) & c D(7 l-9 l) & c D(7 l-10 l) \\ c D(8 l-l) & c D(8 l-2 l) & c D(8 l-3 l) & c D(8 l-4 l) & c D(8 l-5 l) & c D(8 l-6 l) & c D(8 l-7 l) & s^{3} E I & c D(8 l-9 l) & c D(8 l-10 l) \\ c D(9 l-l) & c D(9 l-2 l) & c D(9 l-3 l) & c D(9 l-4 l) & c D(9 l-5 l) & c D(9 l-6 l) & c D(9 l-7 l) & c D(9 l-8 l) & s^{3} E I & c D(9 l-10 l) \\ c D(10 l-l) & c D(10 l-2 l) & c D(10 l-3 l) & c D(10 l-4 l) & c D(10 l-5 l) & c D(10 l-6 l) & c D(10 l-7 l) & c D(10 l-8 l) & c D(10 l-9 l) & s^{3} E I\end{array}\right\}$.

Наступні матриці мають вигляд:

$$
y=\left\{\begin{array}{l}
y_{1} \\
y_{2} \\
y_{3} \\
y_{4} \\
y_{5} \\
y_{6} \\
y_{7} \\
y_{8} \\
y_{9} \\
y_{10}
\end{array}\right\}
$$

$$
\left\{R_{i}\right\}=\left\{\begin{array}{l}
R_{1}=y_{1} \cdot c \\
R_{2}=y_{2} \cdot c \\
R_{3}=y_{3} \cdot c \\
R_{4}=y_{4} \cdot c \\
R_{5}=y_{5} \cdot c \\
R_{6}=y_{6} \cdot c \\
R_{7}=y_{7} \cdot c \\
R_{8}=y_{8} \cdot c \\
R_{9}=y_{9} \cdot c \\
R_{10}=y_{10} \cdot c
\end{array}\right\} \text {. }
$$

Число невідомих прогинів опор у системі (4) дорівнює числу рівнянь, тому матриця $A$ рівняння (6) квадратна, число рядків і стовпців дорівнює 10. Позначимо через $\Delta$ визначник матриці $A$ (7), через $\Delta_{j}$ позначимо визначник, який отримано 3 викреслюванням $j$-го стовпця $(j=1, j=2, j=10)$ i вписуванням на це місце стовпця вільних членів $b_{j}$ матриці $H$ (9). За формулою Крамера, елементи $y_{j}$ матриці (8) можна визначити як

$$
y_{j}=\frac{\Delta_{j}}{\Delta}
$$

Це рівняння, а також вирази $(7,8,9)$, дають змогу розраховувати пружні прогини опор та їх реакції (матриця (10)).
Далі наведено вертикальну жорсткість рейкової нитки в точці контакту 3 колесом. Приймаючи величину зовнішнього навантаження, що дорівнює 1 , визначимо пружні прогини усіх опор $R_{i}$ під дією одиничної сили рівняння (11).

Величину осідання рейкової нитки в точці контакту колеса рейки можна визначити як

$y_{\text {eəp }}=y_{5} \frac{x_{p}}{l}+y_{6} \frac{\left(l_{u}-x_{p}\right)}{l_{u}}+\frac{\left(l_{u}-x_{p}\right)^{2} x_{p}^{2}}{3 E I l_{u}}$

Тоді жорсткість буде дорівнювати

$$
C_{b}=\frac{1}{y_{e \partial}}
$$




\begin{abstract}
Висновки
Запропоновано методику визначення приведеної вертикальної жорсткості рейкової нитки в точці контакту колеса і рейки, яка дає змогу враховувати пружні i геометричні характеристики рейок, жорсткості опор, відстані між ними і розподілену масу колії. Величина цієї жорсткості змінна в часі для кожного колеса у будь-який момент часу і відмінна для різних коліс екіпажу. Запропонована математична модель реалізована в програмному комплексі Matlab.
\end{abstract}

\section{Список використаних джерел}

1. Бесстыковой путь [Текст] / В.Г. Альбрехт, Е. М. Бромберг, Н. Б. Зверев [и др.]. - М. : Транспорт, 1982. - 206 с.

2. Взаимодействие пути и подвижного состава [Текст] / Е. М. Бромберг, М.Ф. Вериго, В. Н. Данилов; под ред. М. А. Фишмана. - М. : Трансжелдориздат, 1956. - 280 с.

3. Шахунянц, Г. М. Железнодорожный путь [Текст] : монография / Г. М. Шахунянц. - М. : Транспорт, 1987. - 497 c.

4. Вериго, М. Ф. Взаимодействие пути и подвижного состава [Текст] / М. Ф. Вериго, А. Я. Коган. - М. : Транспорт, 1986. - 589 с.

5. Белых, К. Д. О нагрузках от колес при расчете железнодорожного пути [Текст] / К. Д. Белых, М. К. Уманов, Г. Н. Малышко // Металлургическая промышленность. - 1976. - № 5. - С. 78-79.

6. Никеров, Н. С. Исследования сил взаимодействия рельсовых нитей и подрельсовых шпальных оснований [Текст] / Н. С. Никеров // Труды ЛИИЖТ. - Л. : ЛИИЖТ, 1977. - Вып. 416. С. 26-35.

7. Климов, В. И. Исследование влияния нелинейных характеристик подрельсового основания пути [Текст] / В. И. Климов, А. В. Рыбкин // Труды ДИИТа. - Днепропетровск: ДИИТ, 1987. Вип. 244/32. - С. 72-84.

8. Даренський, О.М. Теоретичні та експериментальні досліження роботи залізничних колій промислового транспорту [Текст] : монографія / О.М. Даренський, - Харків : УкрДАЗТ, 2011 - 204 с.

9. Даренський, О. М. Математична модель коливань залізничної колії як балки, яка має інерційні характеристики [Текст] / О.М. Даренський, Я. С. Лейбук // Інформаційно-керуючі системи на залізничному транспорті. - Харків: УкрДАЗТ, 2017. - № 2(123). - C. 16-20.

10. Progress on wheel-rail dynamic performance of railway curve negotiation [Text] / Kaiyun Wang, Chao Huang, Wanming Zhai, Pengfei Liu, Shen Wang // Journal of Traffic and Transportation Engineering (English Edition) (2014), 1, P. 209-220.
11. Dailydka, S. Modelling the interaction between railway wheel and rail [Text] / J. Sadeghi, S. Shoja // Transport. - 2008. - T. 23. - №. 3. - C. 236-239.

12. Otero, J. A mathematical model to study railway track dynamics for the prediction of vibration levels generated by rail vehicles [Text] / J. Otero, M. A. Martínez, de los Santos, S. Cardona // Proceedings of the Institution of Mechanical Engineers, Part F: Journal of Rail and Rapid Transit. 2011.

А. Н. Даренский, В. П. Шраменко, Ю. Л. Тулей, А. А. Дудин, Я. С. Лейбук. Математическая модель пути, который имеет инерционные характеристики, под действием скоростного подвижного состава. Разработаны модели и методы определения приведенной вертикальной жесткости рельсовой нити в точке контакта колеса и рельса, которая учитывает упругие и геометрические характеристики рельсов, жесткости опор, расстояния между ними и распределенную массу пути. Величина этой жесткости переменна во времени для каждого колеса в любой момент времени и различна для разных колес экипажа. Предложенная математическая модель реализована в программном комплексе Matlab и позволит в дальнейшем выполнить численные исследования динамики взаимодействия пути и подвижного состава.

Ключевые слова: балка на опорах, математическая модель, динамическая система, «экипаж-путь», приведенная жесткость.

A. N. Darenskiy, V. P. Shramenko, Y. L. Tuley, A. A. Dudin, Y.S. Leibuk. A mathematical model of the rail, which has inertial characteristics, under the action of a speed mobile composition. An investigation into rail track operation under loads from the rolling stock by applying numerical methods makes it possible to obtain information on the impact on track and features of the deflected mode of the whole structure in various operational conditions at much lower costs if compared with conducting experiments. Numerical methods make it possible to specify the input design data, which is virtually impossible in experiments.

However, numerical methods can only be implemented when mathematical models adequately reproduce the actual operation of both the vehicle/track dynamic system and track structure. It refers entirely to simulation of the track/vehicle interaction. Thus, simulation of the track/vehicle interaction is an urgent task.

At present the most widely-used track model is the one 
in which rails are presented as bars of infinite length rested on continuous elastic foundation. However, some specialists consider the model to be rather ideal for railways in terms of track and the technical state of track. Calculation of track as a bar rested on numerous elastic supports with variable characteristics of stiffness under static loads has shown that application of methods of elastic foundation gives results understated by $17-24 \%$ [7]. The study presents mathematic models of the vehicle/track dynamic system, and a design scheme of track presented as a bar on numerous elastic dissipative supports with nonlinear characteristics, which is taken on the base of this system.

The authors developed models and methods to define the reduced vertical stiffness of the track in the wheel/rail contact point, which considers rail elastic and geometric characteristics, stiffness of supports, distance between supports and distributed track mass. The value of stiffness is variable by time for each wheel at any time and various for the vehicle's wheels. The mathematical model proposed has been implemented in Matlab software and will make it possible to conduct numerical research into the track/vehicle dynamics.

Keywords: a bar on supports, the mathematical model, the vehicle / rail, dynamic system, reduced stiffness.

Надійшла 05.06.2018 p.

Даренський Олександр Миколайович, д-р техн. наук, професор кафедри колії та колійного господарства Украӥнського державного університету залізничного транспорту, Харків, Украӥна. E-mail: ppx_xiit@kart.edu.ua https://orcid.org/0000-0001-88715710

Шраменко Володимир Павлович, к.т.н., доцент кафедри колії та колійного господарства УкрДУЗТ, Харків, Україна. E-mail: shramenko@kart.edu.иа https://orcid.org/0000-0002-6939-4445

Тулей Юзеф Леонідович, заступник начальника філї «Південна залізниця» ПАТ «Укрзалізниця» https://orcid.org/0000-0002-0978-3713

Дудін Олексій Аркадійович, к.т.н., доцент кафедри колії та колійного господарства Українського державного університету залізничного транспорту, Харків, Украӥна. E-mail: dudin@kart.edu.иа https://orcid.org/0000-0002-6838-1669

Лейбук Ярослав Сергійович, аспірант кафедри колії та колійного господарства Украйнського державного університету залізничного транспорту, Харків, Україна. E-mail: leibuk@kart.edu.ua https://orcid.org/0000-0002-1810-0910
Aleksandr Darenskiy, Dr.Tech.Sciences, Professor of the Department of Track and Track Facilities, Ukrainian State University of Railway Transport, Kharkiv, Ukraine. Email: ppx_xiit@kart.edu.ua https://orcid.org/0000-0001$\underline{8871-5710}$

Volodymyr Shramenko, Candidate of Techn. Sciences, Docent of the Department of Track and Track Facilities, Ukrainian State University of Railway Transport, Kharkiv, Ukraine. E-mail: $\quad$ shramenko@kart.edu.ua https://orcid.org/0000-0002-6939-4445

Yuzef Tuley, Deputy head of branch "Southern Railway" PAT "Ukrzaliznytsya" https://orcid.org/0000-0002-0978$\underline{3713}$

Aleksey Dudin, Candidate of Techn. Sciences, Docent of the Department of Track and Track Facilities, Ukrainian State University of Railway Transport, Kharkiv, Ukraine. E-mail: dudin@kart.edu.ua https://orcid.org/0000-0002$\underline{6838-1669}$

Yaroslav Leibuk, postgraduate of the Department Track and Track Facilities, Ukrainian State University of Railway Transport, Kharkiv, Ukraine. E-mail: leibuk@kart.edu.ua $\underline{\text { https://orcid.org/0000-0002-1810- }}$ $\underline{0910}$ 